\title{
HEAT LOSS UTILIZATION IN ADEQUATELY HEATED MACHINERY AND CONVERSION OF HEAT ENERGY TO ELECTRICAL ENERGY BY CONVECTION OF AIR
}

\author{
Aditya Dalal \\ Class X, Dhirubhai Ambani International School, Mumbai, India \\ Email: aditya.dalal4@gmail.com
}

\begin{abstract}
This research proposes a novel solution for the minimization of heat loss in industrial machinery without heat exchangers. The device proposed does so by generating electric output from convection in a closed convection system where the heat source is the heat energy lost from the concerned machinery. It also includes a Java program which based on specific input shows the amount of electricity that can be generated harnessing heat loss and therefore, checks whether the said machine can be used for electricity production by the proposed device.
\end{abstract}

Keywords: Thermodynamics, Heat Loss, Energy Degradation, Renewable Energy, Electricity Generation, Invention.

Cite this Article: Aditya Dalal, Heat Loss Utilization in Adequately Heated Machinery and Conversion of Heat Energy to Electrical Energy by Convection of Air. International Journal of Mechanical Engineering and Technology. 11(7), 2020, pp. 15-24.

https://iaeme.com/Home/issue/IJMET?Volume $=11 \&$ Issue $=7$

\section{INTRODUCTION}

Since the invention of machinery, heat loss has only increased radically and has evolved into a major problem that plagues not only a number of industrial firms but also the common society. With heat loss being a major contributing factor for energy degradation, it remains at a position where it leads to losses in not only financial resources, but also capital investment due to reduced productivity and efficiency. Total energy being constant, amount of useful energy therefore, amount of useful energy keeps on declining in accordance with the Second Law of Thermodynamics. The need of the hour is to effectively reduce the amount of degraded energy by harnessing it. Using the algorithm proposed by the US Energy Information Association, the average efficiency of coal-based power production mechanisms alone in the USA was $32.6039178213 \%$ as of 2017. This means that there was a $67.3960821787 \%$ degradation of energy. The device proposed in this report is a novel solution to the aforementioned problem. Without using heat exchangers, this device in the 
constructed closed convectional system can radically reduce heat loss by the generation of electricity.

\section{STRUCTURE}

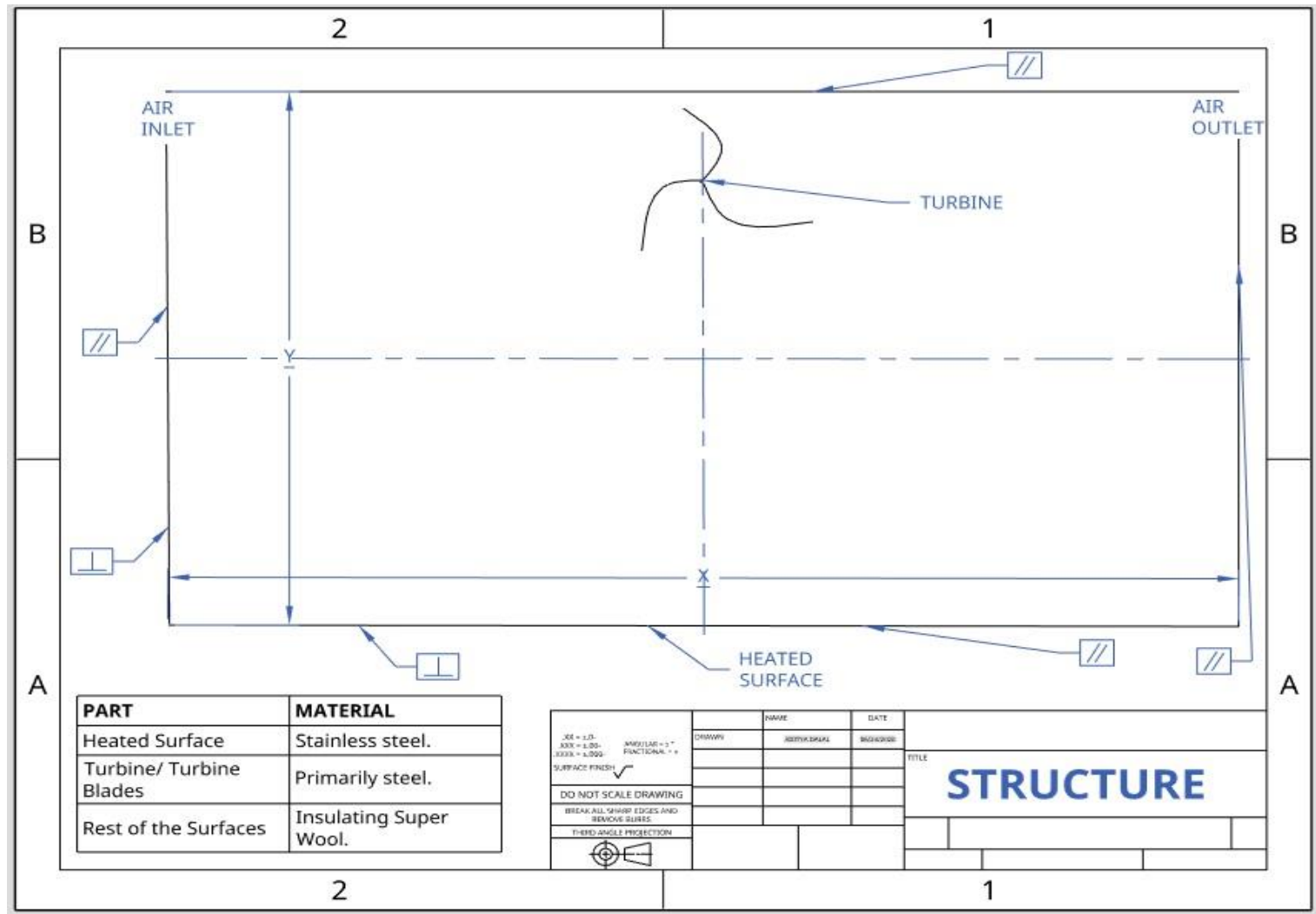

Figure 1 Structure

\subsection{Components}

The device proposed includes the following components:

\subsection{A Container}

This container can be of varied shapes, for example, in Fig 1, it has been shown as a rectangle in a $2 \mathrm{D}$ plane, and is actually a rectangular prism in a $3 \mathrm{D}$ plane. The bottom surface of the container shall be heated by a heat source while the other surfaces are not to be heated by the same. For efficient heating and conduction of heat, the heated surface shall be made of a suitable conducting material, for example, stainless steel. The heated surface may be the surface of an adequately heated machine which may itself act like a heat source as well. The other surfaces shall not be conductors so as to maximize the component of heat transfer through convection of air. Therefore, these surfaces may be made of insulating material that can withstand high temperatures, such as insulating super wool. The container mentioned shall also have an air inlet and an air outlet near the upper surface.

\subsection{Turbine}

A small or light-weighted wind turbine shall also be fitted near the upper surface of the container, such that one of its blades is in line with the air inlet and outlet. The point where the blades of the turbine meet or the center of the turbine shall be on the geometric center of the line joining the midpoints of the upper and the lower surfaces. The turbine blades shall be built of material conventional wind turbines are made, which includes primarily steel. 


\section{FUNCTIONALITY}

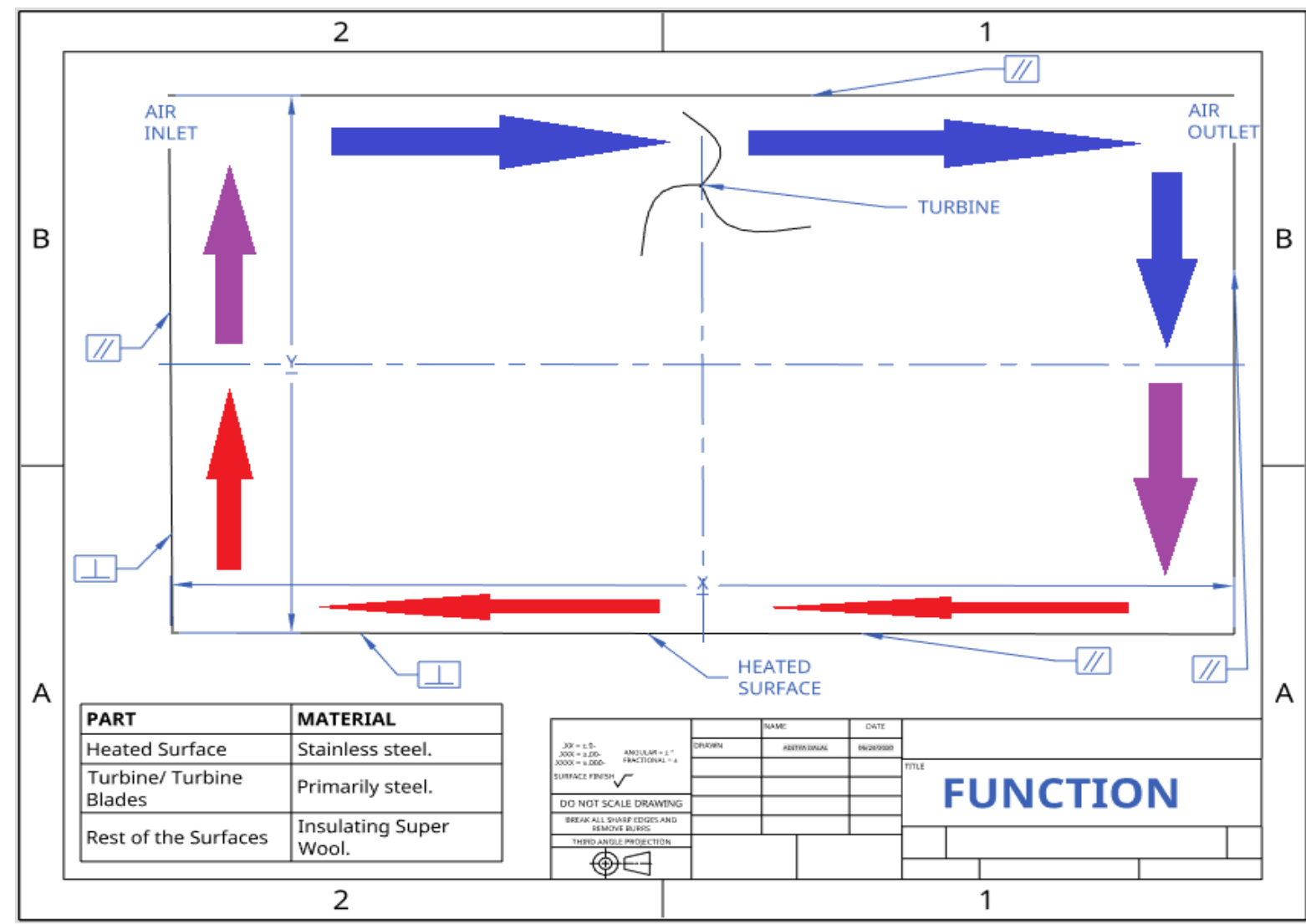

Figure 2 Function

\subsection{Basic Principle}

The device proposed by me works on the principle of using the force applied by air that enters into convection due to an adequate heat flux between 2 masses of air. This force shall be employed to rotate sails of adequately light weight which shall turn as a turbine to create electricity through an AC generator after increasing torque to increase force applied on the rotor connected to the generator, thereby increasing electrical output.

\subsection{Working and Functions of Individual Components}

The heated surface will heat air[1] in contact with it by radiation, due to which Newton's Law of Cooling will be used in calculations later. This heated air has a temperature much higher than the temperature of air outside the device or external air. Therefore, an air inlet has been created for influx of cooler air. This sets up a convectional current with largely laminar current/ flow. However, the heated surface is going to be consistently heated for a long time and once the air mass is consistently heated throughout its volume, recycling of air through a single inlet will become ineffective and slow. Therefore, an air outlet has also been provided for facilitating rapid recycling of air to maintain higher convective velocities of air. Air flowing at such velocities during convection applies force on blades of a turbine (connected to an AC Generator), thereby turning it and generating electricity, which may then be stored for later used or be used immediately. All formulae derivations and equations used have been mentioned later.

[1] Here, fluid can also be written, but for the device proposed, air is used, therefore, air has been written. 


\section{THERMODYNAMICS AND FORMULAE USED}

\subsection{Newton's Law of Cooling}

$\mathrm{P}=\frac{d Q}{d t}=\mathrm{hA} \Delta T$

Where,

$\mathrm{P}=$ Rate of Heat Transfer, $\quad \mathrm{H}=$ Convective Heat Transfer Coefficient,

$\mathrm{Q}=$ Amount of Heat Transferred, $\quad \mathrm{A}=$ Exposed/ Heated Surface Area.

$\Delta T=\left|\mathrm{T}_{2}-\mathrm{T}_{1}\right|$

Where,

$\mathrm{T}_{1}=$ Internal Fluid Temperature,$\quad \mathrm{T}_{2}=$ External Fluid Temperature.

$\therefore \mathrm{Q}_{\mathrm{T}}=\mathrm{hA} \Delta T \mathrm{t}$

\subsection{Equation for Kinetic Energy}

$\mathrm{K}=\frac{1}{2} \mathrm{mv}^{2}$

Where,

$\mathrm{K}=$ Kinetic Energy, $\quad \mathrm{m}=$ Mass of Moving Body/ Fluid,

$\mathrm{v}=$ Velocity of Moving Body/ Fluid.

\subsection{Equation for Velocity of Air/ Wind}

Let $\eta$ be the efficiency of conversion of heat energy to kinetic energy for a time interval of $t$.

$\therefore \mathrm{K}=\eta \mathrm{Q}_{\mathrm{T}}$

If $\mathrm{e}$ is the fraction of heat loss from a machine and $\mathrm{p}$ is its total power, then power lost through heat $\mathrm{P}=\mathrm{pe}$

$\frac{1}{2} \mathrm{mv}^{2}=\eta \mathrm{hA} \Delta T \mathrm{t}$

$\rightarrow \mathrm{v}^{2}=\frac{2 \eta Q \mathrm{~T}}{m} \quad \therefore \mathrm{v}=\sqrt{ } \frac{2 \eta Q \mathrm{~T}}{m}$

OR

$\rightarrow \mathrm{V}^{2}=\frac{2 \eta \mathrm{hA} \Delta T \mathrm{t}}{m}$

$\therefore \mathrm{v}=\sqrt{\frac{2 \eta \mathrm{hA} \Delta T \mathrm{t}}{m}}$

\subsection{Equation for Air/ Wind Power}

$\mathrm{P}=\operatorname{\rho asv}^{3}[1]$

2

Where,

$\mathrm{P}=$ Air/ Wind Power,

$\mathrm{a}_{\mathrm{S}}=$ Area swept by turbine $=\pi \mathrm{r}_{\mathrm{T}}^{2}$ if $\mathrm{r}_{\mathrm{T}}$ is Radius of wind turbine i.e., sum of radius of central piece and length of a blade,

$\mathrm{v}=$ Velocity of air due to convection.

From (3),

$\therefore \mathrm{P}=\operatorname{\rho as}\left(\sqrt{\frac{2 \eta \mathrm{hA} \Delta T \mathrm{t}}{m}}\right)^{3} / 2$ 


\subsection{Equation for Power Output of the Proposed Device}

From Equation for Wind/ Air Power, Power Input or $\mathrm{P}_{\text {INPUT }}=\mathrm{P}=\rho \operatorname{ssv}^{3} / 2$.

The equation for Power Output .i.e. PoutPut is given below as (5)

Let $\eta_{\mathrm{T}}$ be the efficiency of the wind turbine

$\therefore \eta_{\mathrm{T}}=\mathrm{P}_{\text {OUTPUT }} / \mathrm{P}_{\text {INPUT }}$

$\therefore$ PoUTPUT $=\eta_{\text {T }}$ PINPUT

From (4),

$\therefore$ POUTPUT $=\eta_{\mathrm{T}} \rho \mathrm{as}\left(\sqrt{\frac{2 \eta \mathrm{hA} \Delta T \mathrm{t}}{m}}\right)^{3 / 2}$

\subsection{Formula for Heat}

$\mathrm{Q}=\mathrm{mc} \Delta T$

Where,

$\mathrm{Q}=$ Heat gained/ lost, $\mathrm{c}=$ Specific Heat Capacity of the Material of the Body,

$\Delta T=$ Difference between original temperature $t_{1}$ and final temperature $t_{2}=\left|t_{1}-t_{2}.\right|$

\subsection{Principle of Mixtures/ Calorimetry without Phase Change(/S)}

Heat lost by hot body/ bodies in a system = Heat gained by cold body/ bodies in a system considering the system is perfectly insulated

$\therefore \sum_{x=1}^{n} Q_{\mathrm{x}}=\sum_{y=n+1}^{a} Q_{\mathrm{y}}$

\section{APPLICATIONS}

\subsection{Assumptions}

- The turbine has been estimated to be $\mathrm{n}$ rectangular prisms with a hemispherical joint.

- The material insulated by superwool has been not considered in calculations for finding the final temperature of heated air inside the device. This is due to its high insulating capability and high thermal resistance or low thermal conductivity.

- The system has been considered to be a controlled one with negligible heat loss.

- Newton's Law of Cooling has been used to ascertain amount of heat transferred via convection from the heated air to air at room temperature.

- Transmission heat losses have been assumed to be negligible when stating the number of LED street lights the device can power.

- The assumed densities and dimensions have been mentioned directly via substitution in the calculations.

- It is assumed no phase change occurs during the convective heat transfer.

- The air used is assumed to be largely dry air.

- For 2 limits of a physical quantity, an average or arithmetic mean has been considered for calculations, for example $2.5 \mathrm{Wm}^{-2} \mathrm{~K}^{-1}$ and $25 \mathrm{Wm}^{-2} \mathrm{~K}^{-1}$ as convective coefficients of heat transfer of air, an average has been taken as $13.75 \mathrm{~m}^{-2} \mathrm{~K}^{-1}$. 
Heat Loss Utilization in Adequately Heated Machinery and Conversion of Heat Energy to Electrical Energy by Convection of Air

\subsection{General Methodology for Finding Power Output}

\subsubsection{Finding Temperature of Air inside the Device}

Table 1 Finding Temperature of Air Inside the Device

\begin{tabular}{|l|c|c|c|}
\hline \multicolumn{1}{|c|}{ Part } & Volume & Mass & Heat \\
\hline Heated plate (steel) & $\mathrm{V}_{1}=\mathrm{l}_{1} \mathrm{~b}_{1} \mathrm{~h}_{1}$ & $\mathrm{~m}_{1}=\rho_{1} \mathrm{~V}_{1}$ & $\begin{array}{c}\mathrm{Q}_{1}=\mathrm{m}_{1} \mathrm{c}_{1} \Delta \mathrm{T}_{1}= \\
\mathrm{m}_{1} \mathrm{c}_{1}\left(\mathrm{~T}_{1}-\mathrm{T}_{2}\right)\end{array}$ \\
\hline Air & $\mathrm{V}_{2}=\mathrm{l}_{2} \mathrm{~b}_{2} \mathrm{~h}_{2}$ & $\mathrm{~m}_{2}=\rho_{2} \mathrm{~V}_{2}$ & $\begin{array}{c}\mathrm{Q}_{2}=\mathrm{m}_{2} \mathrm{c}_{2} \Delta \mathrm{T}_{2}= \\
\mathrm{m}_{2} \mathrm{c}_{2}\left(\mathrm{~T}_{2}-\mathrm{T}_{3}\right)\end{array}$ \\
\hline Turbine (steel) & $\mathrm{V}_{1}=\mathrm{nl}_{3} \mathrm{~b}_{3} \mathrm{~h}_{3}+2 / 3 \pi \mathrm{r}^{3}$ & $\mathrm{~m}_{3}=\rho_{1} \mathrm{~V}_{3}$ & $\begin{array}{c}\mathrm{Q}_{3}=\mathrm{m}_{3} \mathrm{c}_{1} \Delta \mathrm{T}_{2}= \\
\mathrm{m}_{3} \mathrm{c}_{1}\left(\mathrm{~T}_{2}-\mathrm{T}_{3}\right)\end{array}$ \\
\hline $\begin{array}{l}\text { Upper surface and 2 side surfaces } \\
\text { (superwool insulation) }\end{array}$ & $\mathrm{V}_{4}=3 \mathrm{l}_{1} \mathrm{~b}_{1} \mathrm{~h}_{1}$ & $\mathrm{~m}_{4}=\rho_{3} \mathrm{~V}_{4}$ & $\begin{array}{c}\mathrm{Q}_{4}=\mathrm{m}_{4} \mathrm{c}_{3} \Delta \mathrm{T}_{2}= \\
\mathrm{m}_{4} \mathrm{c}_{3}\left(\mathrm{~T}_{2}-\mathrm{T}_{3}\right)\end{array}$ \\
\hline $\begin{array}{l}\text { 2 side surfaces (superwool insulation) } \\
\text { with air inlet and outlet (total mass is } \\
\text { considered) }\end{array}$ & $\mathrm{V}_{5}=2 \mathrm{l}_{4} \mathrm{~b}_{4} \mathrm{~h}_{4}$ & $\mathrm{~m}_{5}=\rho_{3} \mathrm{~V}_{5}$ & $\begin{array}{c}\mathrm{Q}_{5}=\mathrm{m}_{5} \mathrm{c}_{3} \Delta \mathrm{T}_{2}= \\
\mathrm{m}_{5} \mathrm{c}_{3}\left(\mathrm{~T}_{2}-\mathrm{T}_{3}\right)\end{array}$ \\
\hline
\end{tabular}

By the Principle of Mixtures/ of Calorimetry,

Heat lost by Heated Surface $=$ Heat gained by Air + Heat gained by Turbine + Heat gained by Upper surface and 2 side surfaces + Heat gained by the 2 side surfaces with air inlet and outlet

$$
\begin{aligned}
& \therefore \mathrm{Q}_{1}=\mathrm{Q}_{2}+\mathrm{Q}_{3}+\mathrm{Q}_{4}+\mathrm{Q}_{5} \\
& \therefore \mathrm{T}_{2}=\left(\mathrm{m}_{1} \mathrm{c}_{1} \mathrm{~T}_{1}+\mathrm{m}_{2} \mathrm{c}_{2} \mathrm{~T}_{3}+\mathrm{m}_{3} \mathrm{c}_{1} \mathrm{~T}_{3}+\mathrm{m}_{4} \mathrm{c}_{3} \mathrm{~T}_{3}+\mathrm{m}_{5} \mathrm{c}_{3} \mathrm{~T}_{3}\right) /\left(\mathrm{m}_{1} \mathrm{c}_{1}+\mathrm{m}_{2} \mathrm{c}_{2}+\mathrm{m}_{3} \mathrm{c}_{1}+\mathrm{m}_{4} \mathrm{c}_{3}+\mathrm{m}_{5} \mathrm{c}_{3}\right)
\end{aligned}
$$

\subsubsection{Finding Energy Transferred in Air Due to Convection}

By Newton's Law of Cooling,

$\mathrm{P}=\frac{d Q}{d t}=\mathrm{hA} \Delta T$

Let $\mathrm{Q}_{\mathrm{T}}$ be heat transferred by convection from heated air to air at room Temperature and $\mathrm{T}$ be time for which convection is occurring.

$\therefore \mathrm{Q}_{\mathrm{T}}=\mathrm{hA} \Delta T \mathrm{t}$

\subsubsection{Finding Velocity of Air Due to Convection}

From equation (2),

$\therefore \mathrm{v}=\sqrt{\frac{2 \eta Q_{-} \mathrm{T}}{m}}$

\subsubsection{Finding Power of Air Due to Convection}

By Equation for Wind/ Air Power:

$\mathrm{P}=\frac{\rho \mathrm{a}_{\mathrm{s}} \mathrm{v}^{3}}{2}$

\subsubsection{Finding Power Output of Device}

From equation (5),

$\therefore$ PoutPut $=\eta_{\mathrm{T}} \mathrm{P}_{\text {INPUT }}$ 


\subsection{Application of the Proposed Device in a Power Plant Generator}

\subsubsection{Finding Temperature of Air inside the Device}

Table 2 Finding Temperature of Air inside the Device

\begin{tabular}{|c|c|c|c|}
\hline Part & Volume & Mass & Heat \\
\hline Heated plate (steel) & 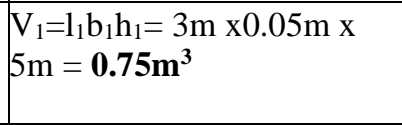 & $\begin{array}{l}\mathrm{m}_{1}=\rho_{1} \mathrm{~V}_{1}= \\
7860 \mathrm{kgm}^{-3} \times 0.75 \mathrm{~m}^{3}= \\
\mathbf{5 8 9 5} \mathbf{k g}^{-}\end{array}$ & $\begin{array}{l}\mathrm{Q}_{1}=\mathrm{m}_{1} \mathrm{c}_{1} \Delta \mathrm{T}_{1}=\mathrm{m}_{1} \mathrm{c}_{1}\left(\mathrm{~T}_{1}-\mathrm{T}_{2}\right)= \\
5895 \mathrm{~kg} \times 502.416 \mathrm{Jkg}^{-1} \mathrm{~K}^{-1} \text { x }(403.15 \mathrm{~K}[2]- \\
\left.\mathrm{T}_{2}\right)=\left(\mathbf{1 1 9 4 0 2 6 4 1 6 . 3 1 - 2 9 6 1 7 4 2 . 3 2 T _ { 2 } ) \mathbf { J }}\right.\end{array}$ \\
\hline Air & $\begin{array}{l}\mathrm{V}_{2}=\mathrm{l}_{2} \mathrm{~b}_{2} \mathrm{~h}_{2}=3 \mathrm{~m} \times 3 \mathrm{~m} \times 5 \mathrm{~m}= \\
\mathbf{4 5 \mathbf { m } ^ { 3 }}\end{array}$ & $\begin{array}{l}\mathrm{m}_{2}=\rho_{2} \mathrm{~V}_{2}= \\
1.225 \mathrm{kgm}^{-3} \times 45 \mathrm{~m}^{3}= \\
\mathbf{5 5 . 1 2 5} \mathrm{kg}\end{array}$ & $\begin{array}{l}\mathrm{Q}_{2}=\mathrm{m}_{2} \mathrm{c}_{2} \Delta \mathrm{T}_{2}=\mathrm{m}_{2} \mathrm{c}_{2}\left(\mathrm{~T}_{2}-\mathrm{T}_{3}\right)=55.125 \mathrm{~kg} \mathrm{x} \\
1005 \mathrm{Jkg}^{-1} \mathrm{~K}^{-1} \mathrm{x}\left(\mathrm{T}_{2}-295.55 \mathrm{~K}\right)= \\
\left(\mathbf{5 5 4 0 0 . 6 2 5} \mathbf{T}_{\mathbf{2}} \mathbf{- 1 6 3 7 3 6 5 4 . 7 1 8 8}\right) \mathbf{J}\end{array}$ \\
\hline Turbine (steel) & $\begin{array}{l}\mathrm{V}_{1}=\mathrm{nl}_{3} \mathrm{~b}_{3} \mathrm{~h}_{3}+2 / 3 \pi \mathrm{r}^{3}=3 \mathrm{x} \\
0.25 \mathrm{~m} \times 0.05 \mathrm{~m} \times 0.05 \mathrm{~m}+ \\
2 / 3 \pi \mathrm{x} \\
(0.05 \mathrm{~m})^{3}=0.001875 \mathrm{~m}^{3} \\
+0.26179938779 \mathrm{~m}^{3}=\mathbf{0 . 2 6 3 6} \\
\mathbf{7 4 3 8 7 7 9} \mathrm{m}^{\mathbf{3}}\end{array}$ & $\begin{array}{l}\mathrm{m}_{3}=\rho_{1} \mathrm{~V}_{3}= \\
7860 \mathrm{kgm}^{-3} \mathrm{x} \\
0.26367438779 \mathrm{~m}^{3}= \\
\mathbf{2 0 7 2 . 4 8 0 6 8 8 0 3} \\
\mathbf{K g}\end{array}$ & $\begin{array}{l}\mathrm{Q}_{3}=\mathrm{m}_{3} \mathrm{c}_{1} \Delta \mathrm{T}_{2}=\mathrm{m}_{3} \mathrm{c}_{1}\left(\mathrm{~T}_{2}-\mathrm{T}_{3}\right)= \\
2072.48068803 \\
\mathrm{Kg} \times 502.416 \mathrm{Jkg}^{-1} \mathrm{~K}^{-1} \times\left(\mathrm{T}_{2}-295.55 \mathrm{~K}\right)= \\
\left(\mathbf{1 0 4 1 2 4 7 . 4 5 7 3 6} \mathrm{T}_{\mathbf{2}}-\mathbf{3 0 7 7 4 0 6 8 6 . 0 2 3}\right) \mathbf{J}\end{array}$ \\
\hline $\begin{array}{l}\text { Upper surface and } 2 \\
\text { side surfaces } \\
\text { (superwool insulation) }\end{array}$ & $\begin{array}{l}\mathrm{V}_{4}=3 \mathrm{l}_{1} \mathrm{~b}_{1} \mathrm{~h}_{1}=3 \times 3 \mathrm{~m} \times 0.05 \mathrm{~m} \\
\times 5 \mathrm{~m}=\mathbf{2 . 2 5 \mathbf { m } ^ { 3 }}\end{array}$ & 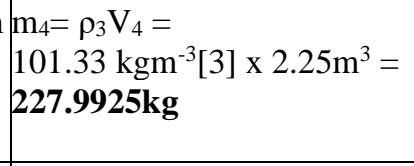 & $\begin{array}{l}\mathrm{Q}_{4}=\mathrm{m}_{4} \mathrm{c}_{3} \Delta \mathrm{T}_{2}=\mathrm{m}_{4} \mathrm{c}_{3}\left(\mathrm{~T}_{2}-\mathrm{T}_{3}\right)= \\
227.9925 \mathrm{~kg} \times 1220 \mathrm{Jkg}^{-1} \mathrm{~K}^{-1}[4] \times\left(\mathrm{T}_{2^{-}}\right. \\
295.55 \mathrm{~K})= \\
\left(278150.85 \mathrm{~T}_{2}-\mathbf{8 2 2 0 7 4 8 3 . 7 1 7 5}\right) \mathbf{J}\end{array}$ \\
\hline \begin{tabular}{|l|}
2 side surfaces \\
(superwool insulation) \\
with air inlet and outlet \\
(total mass is \\
considered)
\end{tabular} & $\begin{array}{l}\mathrm{V}_{5}=2 \mathrm{l}_{4} \mathrm{~b}_{4} \mathrm{~h}_{4}=2 \times 3 \mathrm{~m} 0.05 \mathrm{~m} \\
4.85 \mathrm{~m}=\mathbf{1 . 4 5 5 \mathbf { m } ^ { 3 }}\end{array}$ & $\begin{array}{l}\mathrm{m}_{5}=\rho_{3} \mathrm{~V}_{5}= \\
101.33 \mathrm{kgm}^{-3} \times 1.455 \mathrm{~m}^{3}= \\
\mathbf{1 4 7 . 4 3 5 1 5 k g}\end{array}$ & $\begin{array}{l}\mathrm{Q}_{5}=\mathrm{m}_{5} \mathrm{c}_{3} \Delta \mathrm{T}_{2}=\mathrm{m}_{5} \mathrm{c}_{3}\left(\mathrm{~T}_{2}-\mathrm{T}_{3}\right)= \\
147.43515 \mathrm{~kg} \text { x } 1220 \mathrm{Jkg}^{-1} \mathrm{~K}^{-1} \mathrm{x}\left(\mathrm{T}_{2^{-}}\right. \\
295.55 \mathrm{~K})= \\
\left(\mathbf{1 7 9 8 7 0 . 8 8 3} \mathbf{T}_{\mathbf{2}} \mathbf{- 5 3 1 6 0 8 3 9 . 4 7 0 7}\right) \mathbf{J}\end{array}$ \\
\hline
\end{tabular}

By the Principle of Mixtures/ of Calorimetry,

Heat lost by Heated Surface $=$ Heat gained by Air + Heat gained by Turbine + Heat gained by Upper surface and 2 side surfaces + Heat gained by the 2 side surfaces with air inlet and outlet $\therefore \mathrm{Q}_{1}=\mathrm{Q}_{2}+\mathrm{Q}_{3}+\mathrm{Q}_{4}+\mathrm{Q}_{5}$ $\therefore\left(1194026416.31-2961742.32 \mathrm{~T}_{2}\right) \mathrm{J}=\left(55400.625 \mathrm{~T}_{2}-16373654.7188\right) \mathrm{J}+\left(1041247.45736 \mathrm{~T}_{2}-\right.$ $307740686.023) \mathrm{J}+\left(278150.85 \mathrm{~T}_{2}-82207483.7175\right) \mathrm{J}+\left(179870.883 \mathrm{~T}_{2}-53160839.4707\right) \mathrm{J}$ $\therefore 1194026416.31 \mathrm{~K}-2961742.32 \mathrm{~T}_{2}=55400.625 \mathrm{~T}_{2}-16373654.7188 \mathrm{~K}+1041247.45736 \mathrm{~T}_{2}-$ $307740686.023 \mathrm{~K}+92716.95 \mathrm{~T}_{2}-27402494.5725 \mathrm{~K}+179870.883 \mathrm{~T}_{2}-53160839.4707 \mathrm{~K}$

$\therefore 4516412.13536 \mathrm{~T}_{2}=1604184590.24 \mathrm{~K}$

$$
\begin{aligned}
& \therefore \mathrm{T}_{2}=355.190036287 \mathrm{~K} \\
& \therefore \mathrm{T}_{2}=82.0400362869^{\circ} \mathrm{C}
\end{aligned}
$$

\subsubsection{Finding Energy Transferred in Air Due to Convection}

By Newton's Law of Cooling,

$\mathrm{P}=\frac{d Q}{d t}=\mathrm{hA} \Delta T$

Let $\mathrm{Q}_{\mathrm{T}}$ be heat transferred by convection from heated air to air at room Temperature and $\mathrm{T}$ be time for which convection is occurring.

$\therefore \mathrm{Q}_{\mathrm{T}}=\mathrm{hA} \Delta T \mathrm{t}$

Taking $\mathrm{h}=13.75 \mathrm{Wm}^{-2} \mathrm{~K}^{-1}[5]$,

$\mathrm{A}=\mathrm{l}_{1} \mathrm{~b}_{1}=25 \mathrm{~m}^{2}$,

$\Delta T=\mathrm{T}_{2}-\mathrm{T}_{3}=355.190036287 \mathrm{~K}-295.55 \mathrm{~K}=59.640036287 \mathrm{~K}$,

$\mathrm{t}=1 \mathrm{~s}$ as path of air followed will very less probably be greater than $28.7388956357 \mathrm{~m}$.

$\therefore \mathrm{Q}_{\mathrm{T}}=\mathbf{2 0 5 0 1 . 2 6 2 4 7 3 7 \mathrm { J }}$ 


\subsubsection{Finding Velocity of Air Due to Convection}

From equation (2) taking $\eta=0.9$ due to high efficiency of conversion of heat energy to kinetic energy and taking $\mathrm{m}=55.125 \mathrm{~kg}$,

$\therefore \mathrm{V}=\sqrt{\frac{2 \eta Q_{-} \mathrm{T}}{m}}$

$\therefore \mathrm{v}=25.8733256218 \mathrm{~ms}^{-1}$

\subsubsection{Finding Power of Air Due to Convection}

By Equation for Wind/ Air Power:

$\mathrm{P}=\frac{\rho \mathrm{asv}^{3}}{2}$

$\mathrm{P}=1.225 \mathrm{kgm}^{-3}$

$\mathrm{a}_{\mathrm{s}}=\pi \mathrm{r}_{\mathrm{T}}^{2}\left(\mathrm{r}_{\mathrm{T}}=\mathrm{r}+\mathrm{l}_{3}=0.05 \mathrm{~m}+0.25 \mathrm{~m}=0.3 \mathrm{~m}\right)$

$\therefore \mathrm{a}_{\mathrm{s}}=0.28274333882 \mathrm{~m}^{2}$

$\therefore \mathrm{P}=2999.54400659 \mathrm{~W}$

\subsubsection{Finding Power Output of Device}

From equation (5) and taking $\eta_{\mathrm{T}}=0.5$ [6], $\mathrm{P}_{\mathrm{INPUT}}=2999.54400659 \mathrm{~W}$

$\therefore$ POUTPUT $=\eta_{\text {T }}$ PINPUT

$\therefore$ PoutPut $=1499.77200329 \mathrm{~W}=1.49977200329 \mathrm{~kW}$

$\therefore$ Energy produced per day $\mathrm{E}_{1}$ if time $\mathrm{t}=24 \mathrm{~h}$ assuming no maintenance is required for the power plant generator that day $=P_{\text {OUTPUT }} \mathrm{t}=\mathbf{3 5 . 9 9 4 5 2 8 0 7 9} \mathbf{k W h}$

Taking the wattage of an LED street lamp as 73W [7] and the time of operation a day, taking average operation time per year as 4,100 hours [8] and therefore per day as $11.2328767123 \mathrm{~h}$, the energy usage by an average LED street lamp per day $\mathrm{E}_{2}$ is $0.82 \mathrm{kWh}$.

$\therefore$ Number of street LED lights the device proposed can power daily $(n)=E_{1} / E_{2}=43$ (rounded down.)

\subsection{Examples of Practical Applications of the Device}

A lot of high temperature exhaust gases can be used as a heat source to heat the heated surface.

Exhaust and outlet temperatures for some common fuels - natural gas, liquefied petroleum, diesel and more [9]

Several components of manufacturing plants also witness great amounts of energy degradation, of which heat loss occupies a large part/ fraction. Therefore, the proposed device may also be accordingly fitted onto such devices or machines. The proposed device can also be fitted in heated machinery in oil/ petroleum refineries.

Table 3 Examples of Practical Applications of the Device

\begin{tabular}{|l|c|c|}
\hline \multicolumn{1}{|c|}{ Appliance type } & \multicolumn{2}{c|}{ Exhaust Temperature } \\
\cline { 2 - 3 } & $\left({ }^{\boldsymbol{}} \boldsymbol{F}\right)$ & $\left.\boldsymbol{(}^{\boldsymbol{}} \boldsymbol{C}\right)$ \\
\hline Chemical Oxidation & $1350-1475$ & $730-800$ \\
\hline Annealing furnace & $1100-1200$ & $590-650$ \\
\hline Fluidized-bed combustion & $1600-1800$ & $870-980$ \\
\hline Natural-gas fired heating appliance with draft hood & 360 & 182 \\
\hline Liquefied-petroleum gas-fired heating appliance with draft hood & 360 & 182 \\
\hline
\end{tabular}




\begin{tabular}{|l|c|c|}
\hline Gas-fired heating appliance, no draft hood & 460 & 238 \\
\hline Glass melting furnace & $1200-1600$ & $650-870$ \\
\hline Oil-fired heating appliance, residential & 560 & 293 \\
\hline Oil-fired heating appliance, forced draft over 400.000 Btu/h & 360 & 182 \\
\hline Conventional incinerator & 1400 & 760 \\
\hline Controlled air incinerator & $1800-2400$ & $982-1316$ \\
\hline Pathological incinerator & $1800-2800$ & $982-1538$ \\
\hline Gas turbine exhaust & $700-1100$ & $370-590$ \\
\hline Diesel exhaust & $1000-1200$ & $540-650$ \\
\hline Ceramic kilns & $1800-2400$ & $982-1316$ \\
\hline
\end{tabular}

\section{CHALLENGES FACED AND REMEDIAL MEASURES}

1. The primary problem faced in the implementation of this scheme would be heating the heated plate to adequately high temperatures, or the recognition of machines, such that the required difference in temperature will be adequate for enough power to be applied. Therefore, a majority of machines, if used as the heat source, will be industrial in nature. Testing and modelling are therefore, made difficult.

2. Due to further energy conversions in our device, during electricity generation and in the gear train, there will be some energy degradation. We will employee the following schemes to reduce the same:

- Design an appropriate gear system.

- Decrease mass of rotational blades serving as turbine as larger its weight, larger will be the torque.

- Increase radius of rotational blades of the turbine, if possible.

- Lubrication of moving parts and using ball bearings wherever possible.

Additionally, the efficiency of conversion of heat energy to kinetic or mechanical energy is already very high.

3. Mass popularization of the device in terms of financial viability. This problem can be tackled by seeking government incentives or funds so as to reduce installation and material costs.

\section{CONCLUSION}

It can be concluded that the Heat Loss Harnesser proposed, is a viable, cost- effective and practical device that not only has the capability to convert heat into electricity, but also losses into profits. It will certainly be more useful and efficient in heat loss utilization than contemporary technology like a thermos flask like structure

The electricity stored may also be used to run the machine it is installed on, if it is installed on the machine and if the machine works on electricity, a number of times, thereby ensuring self- sustainability in industries, factories, thermal power plants and a number of places using machinery.

The streets of whole villages can be lighted with just a single such device at an effective cost or even light more than 3 average households in a metropolitan city like Delhi (New Delhi.) [10]

With no fuel required, the fuel costs become non-existent. Therefore, besides nominal maintenance costs, only installation and raw materials cost persist for the device proposed. Huge amounts of money will be saved by owners of industries and consumers.

This device is sure to be a huge success for society as a whole, on a global scale. 
Heat Loss Utilization in Adequately Heated Machinery and Conversion of Heat Energy to Electrical Energy by Convection of Air

\section{REFERENCES}

[1] Asis Sarkar, D. K. (2012). Wind Turbine Blade Efficiency and Power Calculation. International Journal of Scientific and Research Publications.

[2] Breeze, P. (2015, February 15). Why generators are the unsung heroes of power plant efficiency. Retrieved from Power Engineering International: https://www.powerengineeringint.com/coal-fired/the-unsung-hero-of-plant-efficiency/

[3] Morgan Advanced Materials. (n.d.). Superwool HT Felt Data sheet. Retrieved from http://www.morganthermalceramics.com/:

http://www.morganthermalceramics.com/media/4909/sw-felt-data-sheet-english.pdf

[4] Morgan Advanced Materials. (n.d.). Superwool Technical Manual. Retrieved from http://www.morganthermalceramics.com/:

http://www.morganthermalceramics.com/media/1503/14_third_party_testing_factsheet_se pt_14-eng.pdf

[5] Philip Kosky, Robert Balmer, William Keat, George Wise, Chapter 12 - Mechanical Engineering, Editor(s): Philip Kosky, Robert Balmer, William Keat, George Wise, Exploring Engineering (Third Edition), Academic Press, 2013, Pages 259-281, ISBN 9780124158917, https://doi.org/10.1016/B978-0-12-415891-7.00012-1.

(http://www.sciencedirect.com/science/article/pii/B9780124158917000121)

Philip Kosky, R. B. (2013). Exploring Engineering. Academic Press.

[6] Center for Sustainable Systems, University of Michigan. 2019. "Wind Energy Factsheet." Pub. No. CSS07-09.

[7] Pacific Lamp \& Supply Company. (n.d.). How many watts does a street light use? Retrieved from http://www.pacificlamp.com/: http://www.pacificlamp.com/streetlight.asp

[8] Wigan Council. (n.d.). LED Street Lights - Frequently Asked Questions. Retrieved from https://www.wigan.gov.uk/index.aspx: https://www.wigan.gov.uk/Docs/PDF/Resident/Parking-Roads-Travel/LED-street-lightsFAQ.pdf

[9] The Engineering ToolBox. (n.d.). Fuels Exhaust Temperatures. Retrieved from https://www.engineeringtoolbox.com/: $\quad$ https://www.engineeringtoolbox.com/fuelsexhaust-temperatures-d_168.html

[10] Centre for Policy Research. (2017, November 7). Trends in India's Residential Electricity Consumption. Retrieved from https://www.cprindia.org/: https://cprindia.org/news/6519 